\title{
Three-phase fault direction identification method for outgoing transmission line of DFIG-based wind farms
}

\author{
Zhanfeng FAN ${ }^{1}$, Guobing SONG ${ }^{1}$, Xiaoning KANG ${ }^{1}$, \\ Jisi TANG ${ }^{2}$, Xiaobo WANG ${ }^{3}$ (D)
}

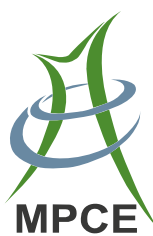

\begin{abstract}
Doubly-fed induction generator (DFIG)-based wind farm has the characteristic of transient fault with low voltage ride through (LVRT) capability. A new three-phase fault direction identification method for the outgoing transmission line of the wind farm is presented. The ability of the new directional relay to differentiate between a three-phase fault in one direction or the other is obtained by using the increment of phase angle difference between the memory voltage signal and the fault current signal within a certain time, and using the amplitude variation of the fault current. It can be inferred that the fault current is supplied by the wind farm whether the phase angle differs or the current amplitude varies considerably. Different fault locations at the outgoing transmission line have been simulated by PSCAD/EMTDC to evaluate the reliability and sensitivity of the proposed technique. Results show
\end{abstract}

CrossCheck date: 20 September 2018

Received: 2 May 2018/Accepted: 20 September 2018/Published online: 27 December 2018

(C) The Author(s) 2018

Xiaobo WANG

zuoluome278@163.com

Zhanfeng FAN

349568751@qq.com

Guobing SONG

song.gb@163.com

Xiaoning KANG

kxn6832@qq.com

Jisi TANG

376556971@qq.com

Xi'an Jiaotong University, Xi'an, China

2 State Grid Beijing Electric Power Company, Beijing, China

3 State Grid Shanxi Maintenance Company, Taiyuan, China that the new directional relay is of faster response when a three-phase fault occurs at the outgoing transmission line of a DFIG-based wind farm.

Keywords Wind farm, Doubly-fed induction generator (DFIG), Directional relay, Outgoing transmission line

\section{Introduction}

With the rapid development of wind generation technology and the increasing growth of wind power capacity in power systems, large-scale wind farms have a great impact on relay protection $[1,2]$. As the electricity collecting element, the outgoing transmission line is quite important for normal operation of a wind farm, especially in a doubly-fed induction generator (DFIG)-based wind farm, which is a widely applied type [3,4]. Thus it is necessary to find a reliable protection scheme for such transmission lines. The directional relay is one of the most important protection elements. A traditional fault component-based directional relay is extensively used in practice because of its simple structure, fast response, and good adaptability to load, fault type and transition resistance. However, the fault characteristics of a wind farm are different from those of conventional power systems [5, 6]. Because of the input of a crowbar protection circuit, the main frequency of the short circuit current fed by a doublyfed wind farm with a capacity of low voltage ride through (LVRT) will be the rotating frequency of the wind turbine before the fault, and it may no longer maintain the power frequency $(50 \mathrm{~Hz})$. This may considerably impact on the performance of the traditional directional relay which compares the phase angles of current and voltage. 
It is necessary to study a new directional relay which is adaptable to the outgoing transmission line of the wind farm. Given the difference of phase angles between fault and load current when a fault occurs forward and backward [7], a direction identification approach has been proposed. However, the method has the adaptability problem in a wind power system because of the fast variation of the load current. Two kinds of directional relays based on a sequence component are presented in [8]: one calculates the ratio of the negative sequence component to the zero sequence component and identifies direction by comparing the ratio with a statistical boundary value; the other compares the values of the fifth harmonic of the zero sequence component with the positive sequence component to determine the fault direction. Both directional relays work well under ideal conditions. However, rich high order harmonics and non-periodic components during a fault in a wind power system will reduce the precision of this method. A new method for discriminating a directional element is proposed in [9]. This method applies the principle that the transient potential of a DFIG has inertia for a short time after a fault. However, due to the short duration of the inertia of the equivalent transient electromotive force (EMF) of the DFIG, this method will fail if the protection cannot effectively determine the fault direction during this period. In [10], a fault current classification method is proposed, and the fault direction is identified according to the difference of fault current waveforms. However, it needs to add frequency tracking links, and the action time for the protection is longer.

This paper purposes a faster direction identification method for the condition that the traditional directional relay cannot identify the fault direction accurately when a three-phase fault occurs. The new method mainly utilizes the characteristics that the short circuit current of the forward fault is usually a non-power frequency attenuation AC component, while the short circuit current of the backward fault is a power-frequency $\mathrm{AC}$ component. If the phase angle difference of the fault current is large after a period of failure, it is considered to be a positive direction export fault; if the phase angle difference is small but the amplitude difference is large, it is still considered as a forward outlet fault; if the phase angle difference and amplitude difference of the fault current calculation are relatively small, it is considered to be a reverse outlet fault of the outgoing line. A large-scale wind farm model is established in PSCAD environment to verify the proposed protection. Simulation results show that the fault direction can be accurately identified on both sides of the line when a three-phase fault occurs.

\section{Adaptability analysis of traditional directional relay to DFIG-based wind farm}

When the voltage measured by a relay drops only a little during a fault, the positive sequence voltage prior the fault is memorized and adopted as the polarized voltage for traditional directional relay [7], as shown in (1):

$-90^{\circ}<\arg \left(\frac{-\dot{U}_{f 1}}{\dot{U}_{m}-\dot{I}_{m} Z_{s e t}}\right)<90^{\circ}$

where $\dot{U}_{f 1}$ is the positive sequence voltage prior to the fault, $\dot{U}_{m}$ and $\dot{I}_{m}$ are the voltage and current respectively measured by the relay, and $Z_{\text {set }}$ is the setting impedance.

When the positive sequence voltage drops below $20 \%$ of its pre-fault value, a positive sequence voltage polarized phase comparison circle is generally used for direction identification, with the memorized positive sequence voltage adopted as the polarized voltage. The operational equation is shown as in (2).

$-90^{\circ}<\arg \left(\frac{-\dot{U}_{p o 1}}{\dot{U}_{m}-\dot{I} Z_{s e t}}\right)<90^{\circ}$

where $\dot{U}_{p o 1}$ is the memorized voltage.

In order to test the function of the traditional directional relay of the outgoing transmission line in a wind farm, the model of a DFIG-based wind farm shown in Fig. 1 is built and simulated in PSCAD/EMTDC. The installed capacity of the wind farm is $300 \mathrm{MW}$. Through a package transformer, DFIG, with a terminal voltage of $0.69 \mathrm{kV}$ and a capacity of $5 \mathrm{MW}$, is connected to a collecting line (35 $\mathrm{kV})$. With the main transformer, the collecting lines are integrated to an outgoing transmission line $(220 \mathrm{kV})$. Thus the wind farm is connected to a $220 \mathrm{kV}$ bus, and the electrical energy is delivered to the power system. The parameters of the simulated model are listed in Table 1 and Table 2.

Figure 2 shows the phase angle comparison between the memory voltage and the measured voltage by directional relay when a three-phase fault occurs at the middle point of the outgoing transmission line. Memory voltage is taken as reference voltage.

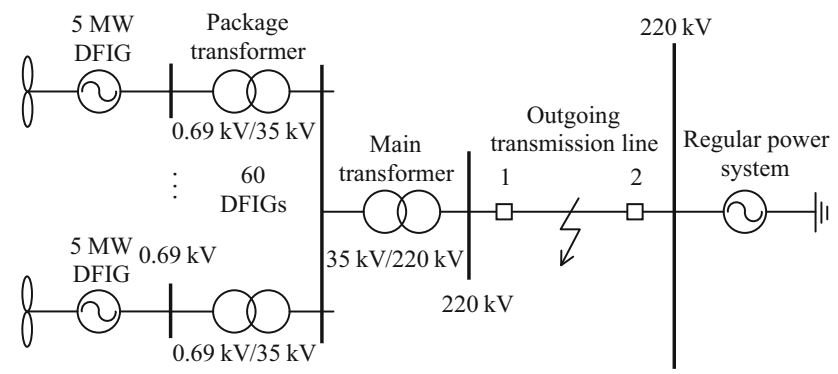

Fig. 1 System topology of DFIG-based wind farm 
Table 1 Parameters of DFIG-based wind farm

\begin{tabular}{lll}
\hline Unit & Parameter & Value \\
\hline Wind turbine & Rated capacity (MW) & 5 \\
& Rated voltage (kV) & 0.69 \\
& Stator resistance (p.u.) & 0.00756 \\
& Stator leakage resistance (p.u.) & 0.1425 \\
& Rotor resistance (p.u.) & 0.00533 \\
& Rotor leakage resistance (p.u.) & 0.1425 \\
& Excitation reactance (p.u.) & 2.1767 \\
Box transformer & Rated capacity (MW) & 7.5 \\
& Rated voltage (kV) & $0.69 / 35$ \\
& Positive sequence leakage reactance & 0.0895 \\
& (p.u.) & \\
& No-load loss (p.u.) & 0.00035 \\
& Copper consumption (p.u.) & 0.0094 \\
\hline
\end{tabular}

As shown in Fig. 2, when a symmetrical short circuit occurs in the forward direction of the wind-side directional relay, the phase angle of the terminal voltage of the wind farm periodically fluctuates. With the LVRT capability, DFIGs switch on a crowbar to protect the converter during the fault when DFIGs can be seen as an induction motor, which leads to a change of frequency. Therefore, a traditional directional relay cannot reliably identify the fault direction. On the other hand, the grid-side directional relay of the outgoing transmission line performs well in this situation. Further simulation shows that if the fault current measured by the directional relay is provided by the power system, the directional relay identifies the fault direction correctly and if the current measured by the directional relay is supplied by the DFIG-based wind farm, the directional relay cannot correctly identify the fault direction.

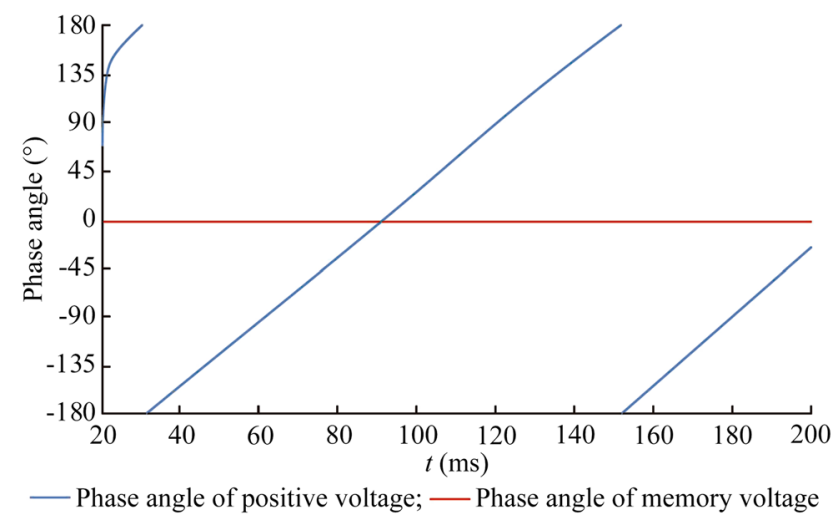

Fig. 2 Phase angle comparison between memory voltage and measured voltage

\section{Fault characteristics of the outgoing line of a DFIG-based wind farm}

The fault current of a crowbar-protected DFIG has three components: (1) decaying DC component, (2) decaying AC component at the rotating frequency of the rotor, (3) steady state fundamental frequency component [8]. Among them, the three phase currents component at the rotating frequency of the rotor can be described as (3):

$\left\{\begin{array}{l}i_{s a \omega_{r}}(t)=\mathrm{e}^{-t / \tau_{r}} a_{\alpha 1} \sin \omega_{r} t+\mathrm{e}^{-t / \tau_{r}} a_{\alpha 2} \cos \omega_{r} t \\ i_{s b \omega_{r}}(t)=\mathrm{e}^{-t / \tau_{r}} a_{\alpha 1} \sin \left(\omega_{r} t-2 \pi / 3\right)+\mathrm{e}^{-t / \tau_{r}} a_{\alpha 2} \cos \left(\omega_{r} t-2 \pi / 3\right) \\ i_{s c \omega_{r}}(t)=\mathrm{e}^{-t / \tau_{r}} a_{\alpha 1} \sin \left(\omega_{r} t+2 \pi / 3\right)+\mathrm{e}^{-t / \tau_{r}} a_{\alpha 2} \cos \left(\omega_{r} t+2 \pi / 3\right)\end{array}\right.$

where $a_{\alpha 1}, a_{\alpha 2}$ are the intrinsic parameters of the DFIG; $\tau_{r}$ is the equivalent time constant of the rotor winding; and $\omega_{r}$ is the angle frequency of the rotor.

Table 2 Parameters of the main transformer of the wind farm and the outgoing transmission line

\begin{tabular}{lll}
\hline Unit & Parameter & Value \\
\hline Main transformer & Rated capacity (MW) & 450 \\
& Rated voltage $(\mathrm{kV})$ & $35 / 220$ \\
& Positive sequence leakage reactance (p.u.) & 0.0895 \\
& No-load loss (p.u.) & 0.00035 \\
& Copper consumption (p.u.) & 0.0094 \\
Outgoing transmission line & Positive sequence resistance of unit length $(\Omega / \mathrm{km})$ & 0.019 \\
& Positive sequence reactance of unit length $(\Omega / \mathrm{km})$ & 0.2463 \\
& Unit length positive sequence capacitor $(\mathrm{nF} / \mathrm{km})$ & 0.2079 \\
& Unit length zero sequence resistance $(\Omega / \mathrm{km})$ & 0.7758 \\
& Zero sequence reactance of unit length $(\Omega / \mathrm{km})$ & 8.703 \\
& Zero sequence capacitance per unit length $(\mathrm{nF} / \mathrm{km})$ & 100 \\
\hline
\end{tabular}




\subsection{Case 1: rotating frequency of rotor far away from power frequency}

When a three-phase fault occurs at the outgoing transmission line of the wind farm, the terminal voltage of the DFIG significantly drops. The memory voltage, which is taken as the polarized voltage, is a steady-state quantity at the power frequency, while the component at the rotating frequency of the rotor takes the biggest part of the stator current [11]. According to (3), the expression of the BC phase-to-phase fault current can be derived as:

$i_{b c}=I_{b c} \sin \left(\omega_{r} t+\theta_{1}\right)$

The BC phase-to-phase memory voltage (positive sequence) is described as:

$u_{b c 1}=U_{b c 1} \sin \left(\omega_{1} t+\theta_{2}\right)$

where $I_{b c}, U_{b c 1}, \theta_{1}$ and $\theta_{2}$ are the amplitudes and initial phase angles of the fault current and memory voltage, respectively.

To extract the real and imaginary parts from the measured data, full-cycle Fourier algorithm is applied. For example, real and imaginary parts of the voltage are calculated by (6) and (7), respectively.

$U_{R}=\frac{2}{T_{1}} \int_{t}^{t+T_{1}} u_{b c 1} \sin \left(\omega_{1} t\right) \mathrm{d} t$

$U_{I}=\frac{2}{T_{1}} \int_{t}^{t+T_{1}} u_{b c 1} \cos \left(\omega_{1} t\right) \mathrm{d} t$

The phase difference between the voltage and stator fault current is introduced as:

$\theta=\arg \left(\frac{\dot{U}_{b c 1}}{\dot{I}_{b c}}\right)$

According to (4)-(8), the expression of $\theta$ can be calculated as:

$$
\begin{aligned}
& \theta=\theta_{1}-\arctan \frac{\left(\omega_{r}+\omega_{1}\right) \sin \left(\left(\omega_{r}-\omega_{1}\right) t+\frac{\omega_{r}}{\omega_{1}} \pi+\theta_{2}\right)}{\left(\omega_{r}+\omega_{1}\right) \cos \left(\left(\omega_{r}-\omega_{1}\right) t+\frac{\omega_{r}}{\omega_{1}} \pi+\theta_{2}\right)} \rightarrow \\
& \leftarrow \frac{\left(\omega_{r}-\omega_{1}\right) \sin \left(\left(\omega_{r}+\omega_{1}\right) t+\frac{\omega_{r}}{\omega_{1}} \pi+\theta_{2}\right)}{\left(\omega_{r}-\omega_{1}\right) \cos \left(\left(\omega_{r}+\omega_{1}\right) t+\frac{\omega_{r}}{\omega_{1}} \pi+\theta_{2}\right)}
\end{aligned}
$$

$\Delta \theta$ is defined as the increment of the phase angle difference between the memory voltage and fault current, which is calculated as:

$\Delta \theta=\max (\theta)-\min (\theta)$

where $\min (\theta), \max (\theta)$ is the maximum and the minimum value of the phase angle difference between memory voltage and fault current respectively. This is measured by the directional relay of wind farm side during the fault

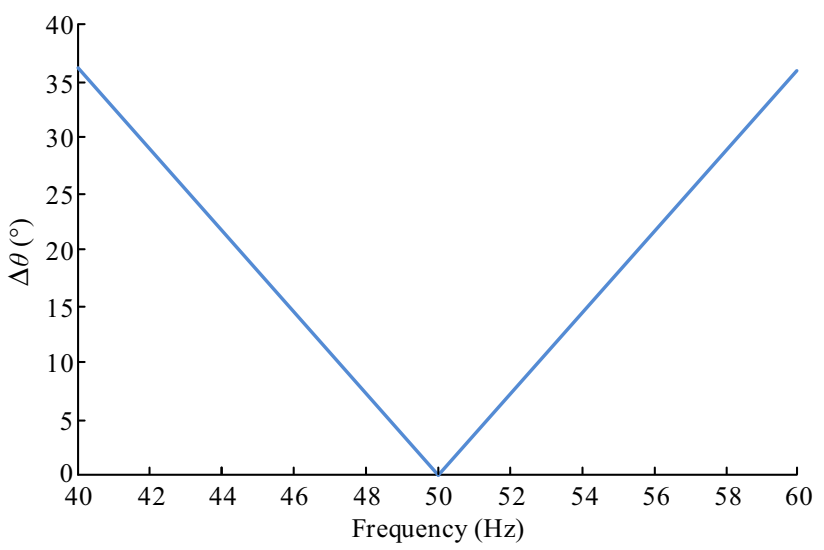

Fig. 3 Relationship between increment of phase angle difference $\Delta \theta$ and rotational frequency prior to the fault

occurring for $20 \mathrm{~ms}$ to $30 \mathrm{~ms}$. The relationship of $\Delta \theta$ and the rotating frequency of the rotor is shown in Fig. 3.

According to Fig. 3, larger deviation of the rotating frequency from the power frequency leads to larger $\Delta \theta$. When the rotating frequency equals the power frequency, $\Delta \theta$ is 0 . At the same time, the fault current supplied by the power system has two components, of which the steady state current takes the larger part, as shown in (11).

$i_{f}(t)=I_{m} \sin \left(\omega_{0} t+\theta_{2}\right)+I_{m} \sin \left(\theta_{2}\right) \mathrm{e}^{-t / \tau}$

where $I_{m}$ is the amplitude of the current supplied by the synchronous generator and $\tau$ is the decaying time constant of the synchronous generator. $\tau$ ranges from $1 \mathrm{~ms}$ to 100 ms while $\theta_{2}$ goes from $0^{\circ}$ to $180^{\circ}$. So the $\Delta \theta$ calculated by the directional relay on the grid side ranges from $0^{\circ}$ to $2.63^{\circ}$.

Based on this characteristic, the threshold of $\Delta \theta$ can be set as $\Delta \theta_{\text {set }}=8^{\circ}$. When $\Delta \theta>\Delta \theta_{\text {set }}$, it means that the fault current is supplied by the DFIG and thereby the fault direction can be identified by the directional relay. When $\Delta \theta<\Delta \theta_{\text {set }}$, there are two possibilities: (1) the fault current is provided by the DFIG with rotating frequency near the power frequency; (2) the fault current is supplied by the power system. Thus further criteria are needed to identify the direction.

\subsection{Case 2: rotating frequency of rotor close to power frequency}

According to (9) and (10), when the rotating frequency of the rotor ranges from $47.83 \mathrm{~Hz}$ to $52.17 \mathrm{~Hz}, \Delta \theta$ calculated by the directional relay would be less than $8^{\circ}$. On the other hand, the fault current supplied by the wind farm decays quickly while the fault current supplied by the regular power system stays relatively stable. A further algorithm on quantity amplitude shows that the maximum 
error is $3.38 \%$ in this frequency range $(47.83 \mathrm{~Hz}$ to 52.17 $\mathrm{Hz}$ ). Therefore, when $\Delta \theta$ is small enough, the decay rate of the fault current amplitude calculated by a Fourier algorithm can be utilized as a complementary criterion for the directional relay.

When the voltage seriously drops during a three-phase short circuit, the steady state fundamental frequency component of the fault current supplied by the wind farm can be ignored. And the fault current has only a decaying $\mathrm{AC}$ component at the rotating frequency of the rotor [9]. The fault current of the wind farm is:

$i_{k}(t)=I_{m} \mathrm{e}^{-t / \tau_{r}} \cos \left(\omega_{r} t+\alpha_{1}\right)$

The amplitude of the decaying AC component decays exponentially.

In order to reflect the amplitude variation of the fault current, the current decay rate $d$ is defined as:

$d=\frac{\left|I_{k}\left(t_{0}\right)-I_{k}\left(t_{T / 2}\right)\right|}{I_{k}\left(t_{0}\right)} \times 100 \%$

where $I_{k}\left(t_{0}\right)$ and $I_{k}\left(t_{T / 2}\right)$ are current amplitudes at the moment of fault occurrence and half a sampling cycle of the full-cycle Fourier algorithm, respectively.

During a fault, the damping rate of the decaying AC component is determined by the rotor's decay time constant which can be expressed as [10]:

$\tau_{r}=\frac{X_{r}+\frac{\left(X_{s}+X_{e}\right) X_{m}}{X_{s}+X_{e}+X_{m}}}{\omega_{0}\left(R_{r}+R_{c b}\right)}$

where $X_{s}, X_{r}$ are the leakage reactances of the stator and rotor windings respectively; $R_{r}$ is the rotor resistance; $X_{m}$ is the magnetizing reactance; $X_{e}$ is the equivalent reactance from the DFIG's terminal and the fault point; $R_{c b}$ is the crowbar resistance; and $\omega_{0}$ is the angular frequency corresponding to the power frequency.

The current decay rate is calculated when a three-phase fault occurs at the outgoing line in a DFIG-based wind farm with classical parameters which can be found in [12-16]. The value of the crowbar resistance normally ranges from $10 R_{r}$ to $30 R_{r}[17,18]$. According to (14), the decay time constant varies from $0.3 \mathrm{~ms}$ to $3.19 \mathrm{~ms}$. Thus the decay rate of the current varies from $26.91 \%$ to $96.43 \%$.

If the fault current is supplied by a regular power system, according to (11), the decay rate of current is calculated in the range of $[0 \%, 10.51 \%]$.

To sum up, based on the calculated results, the threshold value of criterion $d_{\text {set }}$ can be set at $20 \%$.

\section{New criterion for directional relay}

Based on the above analysis, the principle of the new criterion for the directional relay is based on two quantities: the increment of phase angle difference between the fault current and memory voltage $\Delta \theta$ and the decay rate of the fault current $d$. If $\Delta \theta$ calculated by directional relay is larger than $\Delta \theta_{\text {set }}=8^{\circ}$, it means that the fault current is provided by the DFIG-based wind farm. Otherwise, when $\Delta \theta$ is less than $\Delta \theta_{\text {set }}$, the supplier of the fault current can be determined with the help of $d$. If $d$ is larger than $d_{\text {set }}=20 \%$, the DFIG wind farm supplies the fault current; otherwise, the fault current is provided by the power system. According to the provider of the fault current, it is easy to identify the direction of the fault. The flowcharts of the proposed direction identification criterion for the directional relays at two ends of the outgoing transmission line are shown in Fig. 4.

\section{Simulation and verification}

This section will test the performance of the direction identification criterion proposed in last section.

\subsection{Analysis of influencing factors}

Different speeds of a wind turbine will affect the value of measured $\Delta \theta$. A smaller crowbar resistor and a shorter outgoing line will cause a larger stator time constant, which will influence the current decay rate $d$. The wind farm integration shown in Fig. 1 is built, and different cases are simulated to analyze the effect of these three factors on the proposed directional relay criterion.

\subsubsection{Rotating frequency of DFIG}

The experimental relation between the calculated $\Delta \theta$ and the rotating frequency of the rotor is shown in Fig. 5.

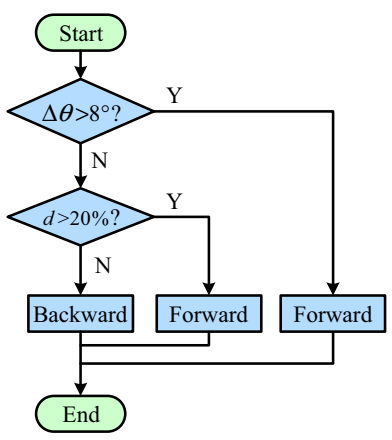

(a) Relay on wind farm side

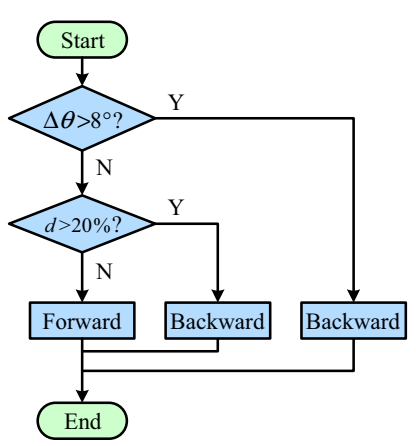

(b) Relay on power system side
Fig. 4 Flowchart of the proposed direction identification criterion 
When the rotating frequency is close to the power frequency, $\Delta \theta$ is relatively small. When the rotating frequency ranges from $45.3 \mathrm{~Hz}$ to $53.8 \mathrm{~Hz}$, the value of $\Delta \theta$ is less than $8^{\circ}$, which basically coincides with the theoretical analysis shown in Fig. 3. The value of $\Delta \theta$ would not decrease to $0^{\circ}$ when the rotating frequency equals the power frequency because of the calculation error caused by the decaying amplitude of the fault current at the rotating frequency.

\subsubsection{Value of crowbar resistance}

When a three-phase fault occurs at the end of the outgoing transmission line on the wind farm side, the amplitude of the fault current has been calculated with crowbar resistance set at $10 R_{r}, 20 R_{r}$ and $30 R_{r}$.

As shown in Fig. 6, a larger crowbar resistance results in a larger decay rate of the current amplitude. Figure 7 depicts the relation between the current decay rate and crowbar resistance. It can be seen that with the increasing crowbar value, the current decay rate rises considerably from $53.04 \%$ to $87.40 \%$.

\subsubsection{Length of outgoing transmission line}

The relation between the current decay rate and the length of the outgoing transmission line is shown in Fig. 8. It can be seen that the current decay rate has a slight growth with length increasing length of the outgoing transmission line.

\subsection{Simulation of directional relay performance}

The simulation model of a DFIG-based wind farm shown in Fig. 1 has been built in PSCAD/EMTDC to test

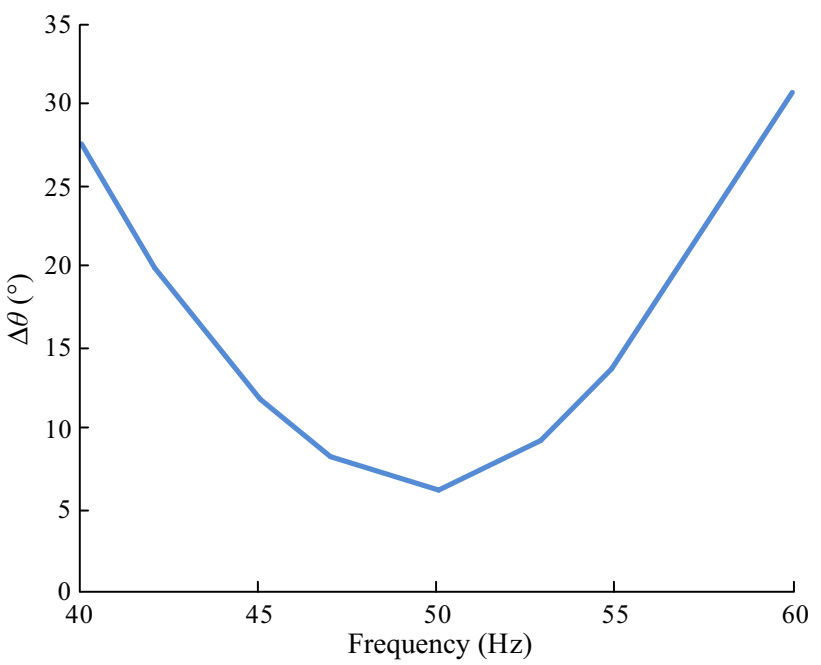

Fig. 5 Experimental relationship between $\Delta \theta$ and rotor's rotating frequency

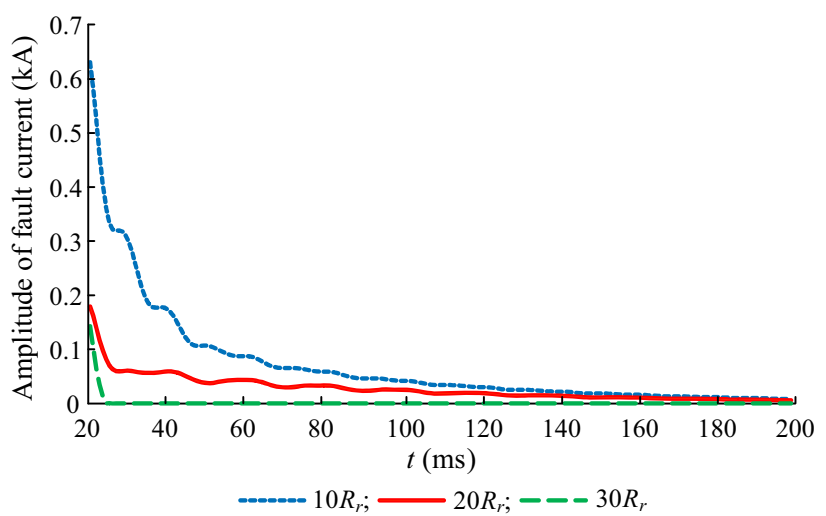

Fig. 6 Amplitude of current with different crowbar resistances

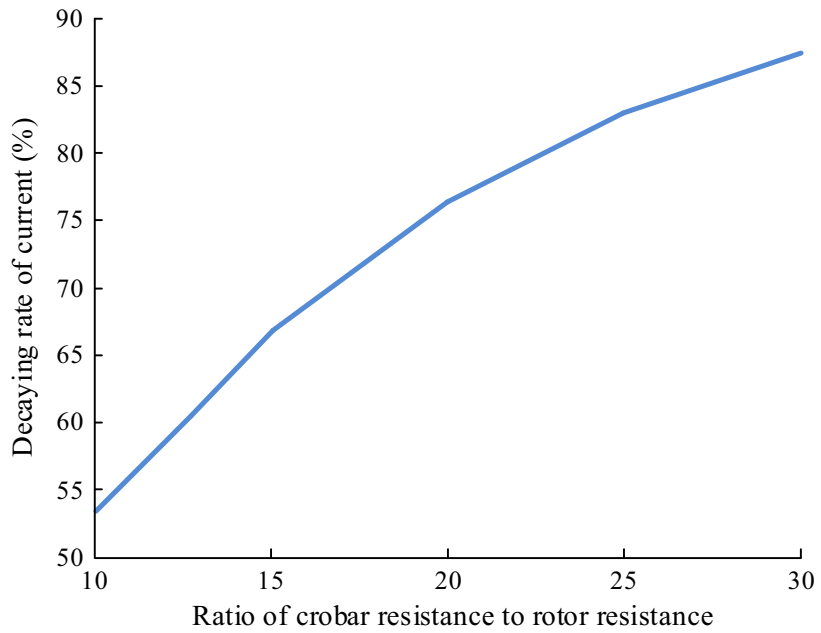

Fig. 7 Relation between current decay rate and crowbar resistance

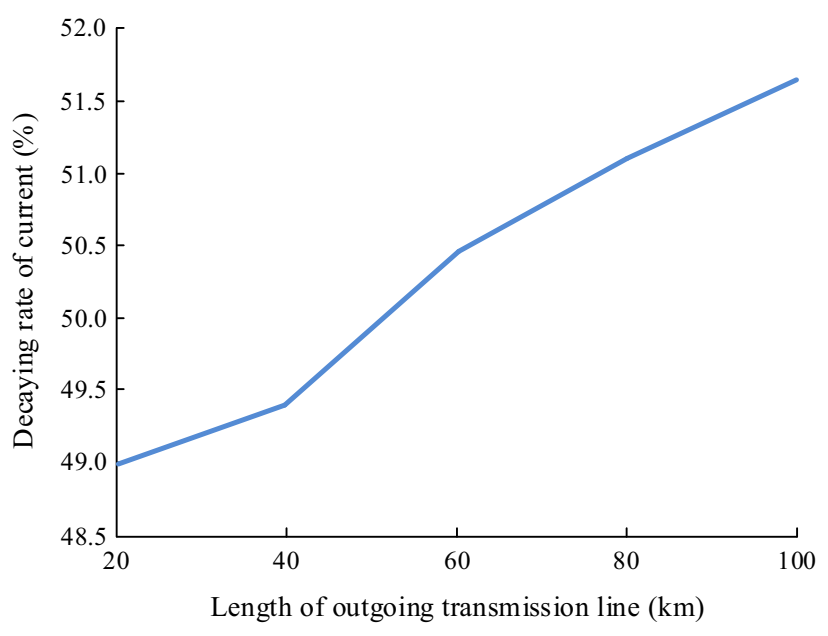

Fig. 8 Relation between current decay rate and the length of the outgoing transmission line

the performance of the proposed directional relay criterion. The value of $\theta$ recorded by the wind farm side directional relay is shown in Figs. 9 and 10 during a forward fault and 


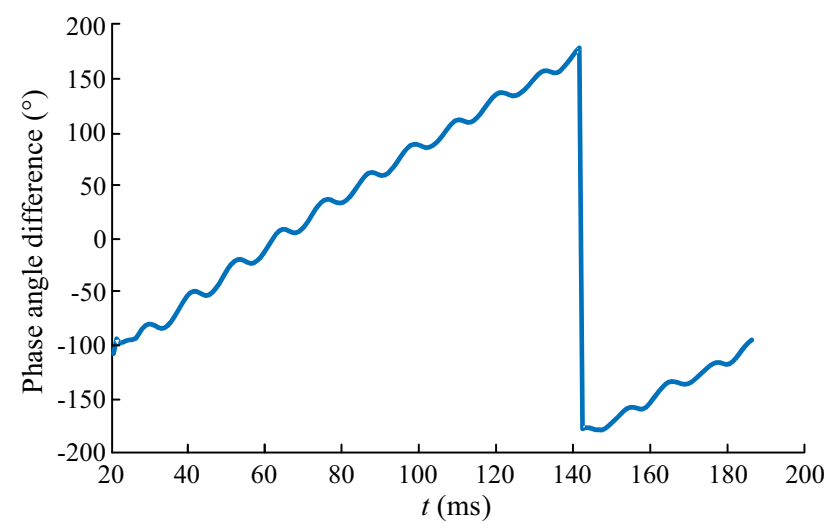

Fig. 9 Value of $\theta$ recorded by directional relay on wind farm side when a forward fault occurs at $50 \mathrm{~km}$ away from the relay location

a backward fault respectively. The rotating frequency of the rotor is 0.8 times of the power frequency.

In Fig. 9, there is $\Delta \theta=21.3^{\circ}$, which is larger than $8^{\circ}$. Thus the directional relay detects a forward fault. In Fig. $10, \Delta \theta=0.33^{\circ}$, which is less than $8^{\circ}$. Thus the decay rate of the current amplitude is needed to identify the fault direction. The amplitude of the fault current is shown in Fig. 11 where $d=1.41 \%$ is less than $20 \%$. Therefore, the directional relay detects a backward fault.

The value of $\theta$ recorded by the wind farm side directional relay is shown in Figs. 12 and 13 during a forward and backward fault respectively. The rotating frequency of the rotor is very close to the power frequency.

In Fig. $12, \Delta \theta=7.17^{\circ}$, which is less than $8^{\circ}$. So the decay rate of the current amplitude is needed to identify the fault direction. The amplitude of the fault current is shown in Fig. 14, where $d=33.18 \%$ is larger than 20\%. Thus the directional relay detects a forward fault.

In Fig. $13, \Delta \theta=0.30^{\circ}$, which is also less than $8^{\circ}$. So the decay rate of current amplitude also is needed. The amplitude of the fault current is shown in Fig. 15, where $d=0.60 \%$ is less than $20 \%$. Therefore, the directional relay detects a backward fault.

Simulations under different conditions are completed and the results are shown in Tables 3 and 4 .

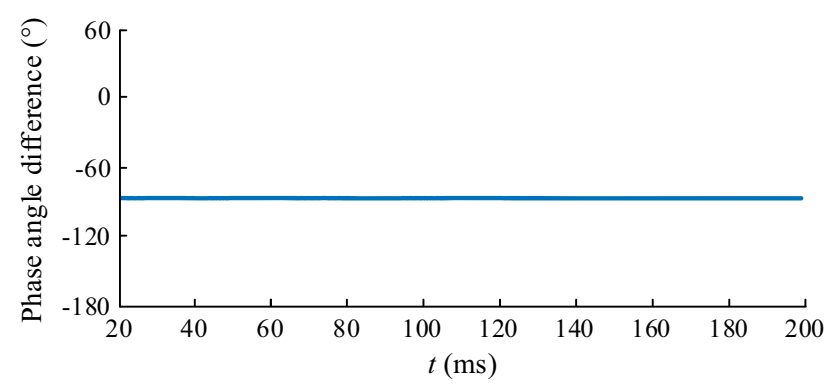

Fig. 10 Value of $\theta$ recorded by directional relay on wind farm side when a backward fault occurs near the relay location

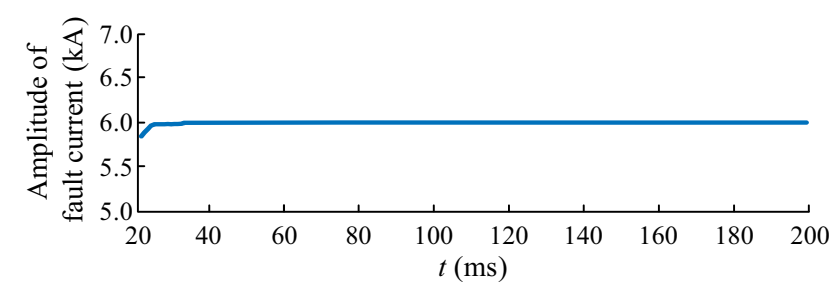

Fig. 11 Amplitude of fault current measured by directional relay on wind farm side when a backward fault occurs near the relay location

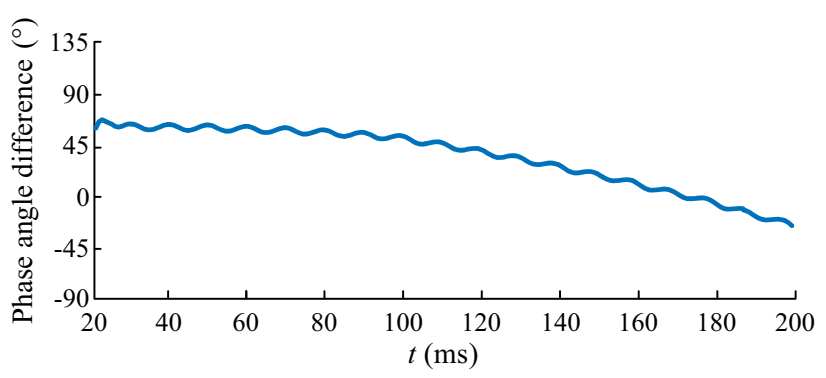

Fig. 12 Value of $\theta$ recorded by directional relay on wind farm side when a forward fault occurs at $50 \mathrm{~km}$ away from relay location (under power frequency)

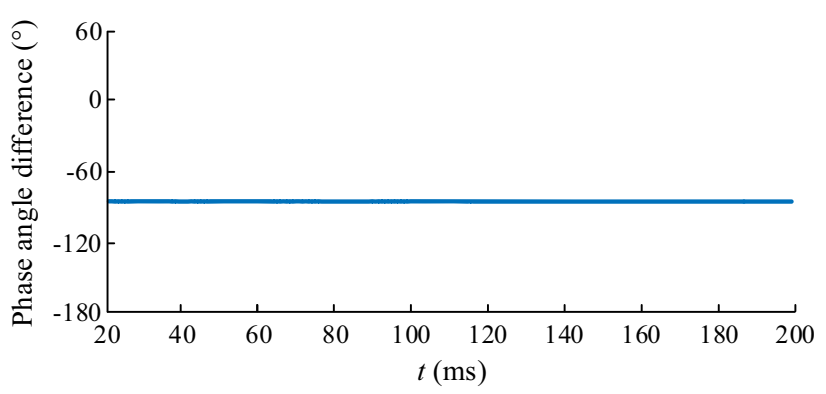

Fig. 13 Value of $\theta$ recorded by directional relay on wind farm side when a backward fault occurs near the relay location (under power frequency)

It can be seen that with the new direction identification criterion, the directional relays on both sides of the outgoing transmission line of the DFIG-based wind farm can quickly provide a correct fault direction. The identification process takes just $30 \mathrm{~ms}$.

Compared with the direction identification method given in [11], the new criterion proposed in this paper has the following advantages:

1) At the moment when the three-phase fault occurs, the frequency of the fault current provided by the DFIG deviates from the power frequency immediately. Frequency tracking according to [11] consumes more time. The directional relay presented in this paper only needs to calculate the increment of phase angle 


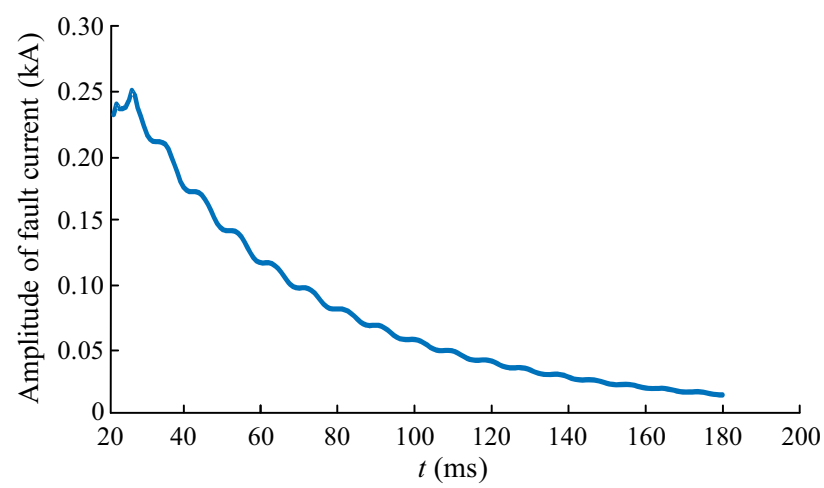

Fig. 14 Amplitude of fault current measured by directional relay on wind farm side when a forward fault occurs near relay location

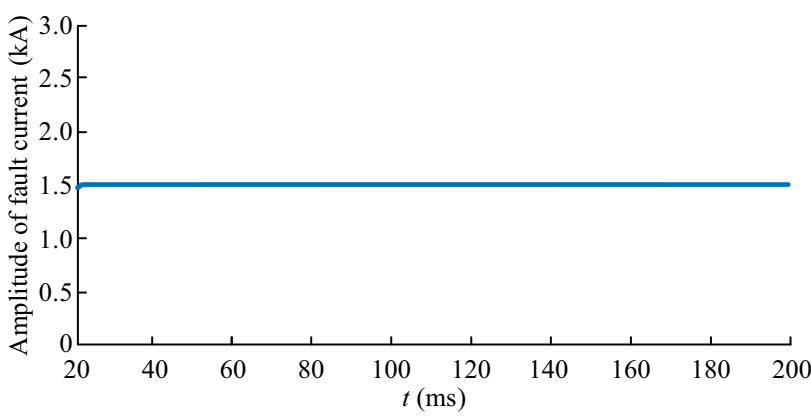

Fig. 15 Amplitude of fault current measured by directional relay on wind farm side when a backward fault occurs near relay location (under power frequency)

difference $\Delta \theta$ and the decay rate of the fault current $d$, which avoids frequency tracking and is time saving.

2) The directional relay in [11] takes $40 \mathrm{~ms}$ to detect the fault direction while the new relay only needs $30 \mathrm{~ms}$.
Table 4 Performance of new directional relay on system side under different conditions

\begin{tabular}{llll}
\hline Condition & $\begin{array}{l}\text { Rotating speed of } \\
\text { rotor (p.u) }\end{array}$ & Results & $\begin{array}{l}\text { Reaction } \\
\text { time }(\mathrm{ms})\end{array}$ \\
\hline $\begin{array}{c}\text { Backward fault at the } \\
\text { terminal }\end{array}$ & 1.2 & Backward & 30 \\
& 1.0 & Backward & 30 \\
Fault point away from & 0.8 & Backward & 30 \\
relay 0 km & 1.0 & Forward & 30 \\
& 1.2 & Forward & 30 \\
Fault point away from & 0.8 & Forward & 30 \\
relay 40 km & 1.0 & Forward & 30 \\
& 1.2 & Forward & 30 \\
Fault point away from & 0.8 & Forward & 30 \\
relay 100 km & 1.0 & Forward & 30 \\
& 1.2 & Forward & 30 \\
& & Forward & 30 \\
\hline
\end{tabular}

3) This paper comes up with the new criterion based on $\Delta \theta$ and the comparison of decay rate of current between the DFIG-based wind farm and a regular power system. Reference [11] only uses the current decay rate of a regular power system.

\section{Conclusion}

This paper presents a new direction identification method for a three phase short circuit in the outgoing transnmission line of a DFIG-based wind farm with the following characteristics:

Table 3 Performance of new directional relay on wind farm side under different conditions

\begin{tabular}{llll}
\hline Condition & Rotating speed of rotor (p.u) & Results & Reaction time (ms) \\
\hline Backward fault at the terminal & 0.8 & Backward & 30 \\
& 1.0 & Backward & 30 \\
Fault point away from relay $0 \mathrm{~km}$ & 1.2 & Backward & 30 \\
& 0.8 & Forward & 30 \\
Fault point away from relay $40 \mathrm{~km}$ & 1.0 & Forward & 30 \\
& 1.2 & Forward & 30 \\
Fault point away from relay $100 \mathrm{~km}$ & 0.8 & Forward & 30 \\
& 1.0 & Forward & 30 \\
\end{tabular}


1) When a three-phase fault occurs in the outlet of the wind farm, the input of the crowbar circuit makes the characteristic of the short circuit current of the DFIG quite different from that of the traditional synchronous machine, which eventually leads to malfunction or rejection of the traditional directional protection elements using the memory voltage as the polarization voltage.

2) When the three-phase short circuit fault occurs in the outlet of the transmission line, and the rotating frequency of the DFIG is close to the power frequency, the phase angle calculated by the short circuit current provided by the fan side varies linearly with time. When the rotating frequency of the fan is far away from the power-frequency, the calculation of the circuit current of DFIG is more stable, but the calculated current amplitude will fade with time. When a three-phase short-circuit backward fault occurs at the outlet of the transmission line, the phase angle and amplitude calculated by the short-circuit current provided by the system side are relatively stable.

3) According to the above fault characteristics, a new direction element criterion for the outgoing transmission line of the wind farm is put forward. If the phase angle difference of the fault current is large after a period of failure, it is considered to be a positive direction export fault; if the phase angle difference is small but the amplitude difference is large, it is still considered as a forward outlet fault; If the phase angle difference and amplitude difference of the fault current calculation are relatively small, it is considered to be the reverse outlet fault of the outgoing transmission line.

4) Simulation results show that, when the new direction element criterion is adopted, the fault direction can be correctly identified when three-phase faults occur in the forward and backward directions of the outgoing transmission line, and are not affected by factors such as the rotating frequency of the fan, the resistance value of the crowbar and the length of the line.

Acknowledgment This work was supported by National Basic Research Program of China (No. 2012CB215105).

Open Access This article is distributed under the terms of the Creative Commons Attribution 4.0 International License (http:// creativecommons.org/licenses/by/4.0/), which permits unrestricted use, distribution, and reproduction in any medium, provided you give appropriate credit to the original author(s) and the source, provide a link to the Creative Commons license, and indicate if changes were made.

\section{References}

[1] Pradhan AK, Gza J (2007) Adaptive distance relay setting for lines connecting wind farms. IEEE Trans Energy Convers 22(1):289-299

[2] Zhang BH, Guo DY, Wang J et al (2012) Configuration, cooperation and existing problems of wind farm relay protection. In: Proceedings of 2012 11th international conference on environment and electrical engineering (EEEIC), Venice, Italy, 18-25 May 2012, 5 pp

[3] Viraj PM, Rama R (2008) Impact of distributed generation on distance protection performance-a review. In: Proceedings of 2008 IEEE PES general meeting, Pittsburgh, USA, 20-24 July 2008, 7 pp

[4] Maryam K, Hosein KK (2011) Effect of wind turbines equipped with doubly-fed induction generators on distance protection. In: Proceedings of 2011 international conference on advanced power system automation and protection (APAP), Beijing, China, 16-20 October 2011, 5 pp

[5] Li W, Pupu C, Xiaodong L et al (2018) Modeling of complete fault ride-through processes for DFIG-based wind turbines. Renew Energy 118:1001-1014

[6] Simon DR, Paula SP, Johan D (2010) Impact of wind turbines equipped with doubly-fed induction generators on distance relaying. In: Proceedings of 2010 IEEE PES general meeting, Providence, USA, 25-29 July 2010, 6 pp

[7] Eissa M (2013) Current directional protection technique based on polarizing current. Int $\mathrm{J}$ Electr Power Energy Syst 44(1):488-494

[8] Petit M, Le PX, Garcia SL (2010) Directional relays without voltage sensors for distribution networks with distributed generation: use of symmetrical components. Electr Power Syst Res 80(10): 1222-1228

[9] Yu C, Minghao W, Xianggen Y et al (2018) Distance protection for transmission lines of DFIG-based wind power integration system. Int J Electr Power Energy Syst 100:438-448

[10] Ali H, Maher AA, Ehab FE (2014) Three-phase fault direction identification for distribution systems with DFIG-based wind DG. IEEE Trans Sustain Energy 5(3):747-756

[11] Ali H, Maher AA, Ehab FE (2014) Distance protection of lines connected to induction generator-based wind farms during balanced faults. IEEE Trans Sustain Energy 5(4):1193-1203

[12] Qinhao L, Yongjun Z, Weipeng Y et al (2012) A study on influence of wind power on positive sequence voltage polarized impedance relay. In: Proceedings of 2012 IEEE power engineering and automation conference (PEAM), Wuhan, China, 14-16 September 2012, 4 pp

[13] Kong X, Zhang Z (2014) Fault current study of wind turbine driven DFIG with crowbar protection. Elektrotehniški Vestnik 81(1-2):57-63

[14] Yue M, Xingying C, Kun Y et al (2014) Analysis of short circuit current of DFIG-based wind generation system under different types of short circuits. Proc CSU-EPSA 26(2):60-65

[15] Mostafa K, Xiaoning K, Guobing S et al (2015) Modeling and fault analysis of doubly fed induction generators for Gansu wind farm application. Can J Electr Comput Eng 38(1):52-64

[16] We ZP, Zheng T, Li J (2013) Short circuit current analysis of DFIG with crowbar under unsymmetrical grid fault. In: Proceedings of 2013 2nd renewable power generation conference (RPG), Beijing, China, 9-11 September 2013, 4 pp

[17] Jiangbing $\mathrm{H}$, Dan S, Yikang $\mathrm{H}$ et al (2006) Modeling and control of DFIG wind energy generation system under grid voltage dip. Autom Electric Power Syst 30(8):21-26 
[18] Lie X, Cartwright P (2006) Direct active and reactive power control of DFIG for wind energy generation. IEEE Trans Energy Convers 21(3):750-758

Zhanfeng FAN received the M.Sc. degree from Huazhong University of Science and Technology, Wuhan, China, in 2009, and is currently pursuing the Ph.D. degree at Xi' an Jiaotong University. His research interests include transmission line fault location and protection.

Guobing SONG received the Ph.D. degree from Xi'an Jiaotong University, Xi'an, China, in 2005. Currently he works in Xi'an Jiaotong University. His research interests include transmission line fault location and protection.
Xiaoning KANG received the Ph.D. degree from Xi'an Jiaotong University, Xi'an, China, in 2006. Currently he works in the Xi'an Jiaotong University. His research interests include fault location, substation automation and transformer protective relaying.

Jisi TANG received the M.Sc. degree from Xi' an Jiaotong University, Xi' an, China, in 2017. His research interests include transmission line fault location and protection for renewable energy integration system.

Xiaobo WANG received the M.Sc. degree from Xi'an Jiaotong University, Xi' an, China, in 2017. His research interests include wind generation and protection. 